\title{
Effects of gamma radiation on the thermoanalytical, structural and pasting properties of black rice (Oryza sativa L.) flour
}

\author{
Vivian Cristina Ito ${ }^{1}$ Camila Delinski Bet ${ }^{1} \cdot$ José Pedro Wojeicchowski $^{1}$. \\ Ivo Mottin Demiate ${ }^{1} \cdot$ Marta Helena Fillet Spoto $^{2} \cdot$ Egon Schnitzler $^{1}$ • \\ Luiz Gustavo Lacerda ${ }^{1}$ (D)
}

Received: 7 July 2017/ Accepted: 12 October 2017/Published online: 23 October 2017

(C) Akadémiai Kiadó, Budapest, Hungary 2017

\begin{abstract}
The effects of different doses of gamma radiation on the thermoanalytical, structural and pasting properties of black rice (Oryza sativa L.) flour were studied using thermogravimetry and derivative thermogravimetry (TG-DTG), differential scanning calorimetry, X-ray diffraction (XRD), field emission gun-scanning electron microscopy (FEG-SEM) and pasting properties (RVA) analysis. The thermogravimetric curves showed four mass losses. A small displacement was observed for the second loss, which occurred for the irradiated flours, compared to the control sample. The irradiated samples showed a slight decrease in the thermal parameters: initial temperature $\left(T_{\mathrm{o}}\right)$, peak temperature $\left(T_{\mathrm{p}}\right)$ and gelatinisation enthalpy $(\triangle H)$. All the black rice flours exhibited A-type crystallinity pattern, and the gamma radiation did not change the XRD patterns or the degree of crystallinity. The microimages obtained using FEG-SEM showed a composite of organic and heterogeneous material; after gamma radiation, some changes occurred, such as cracks, pores and smaller fragments. The pasting properties decreased significantly with irradiation. The decrease in setback and breakdown viscosity after irradiation suggested an indication that it may be possible to improve the quality of food
\end{abstract}

Luiz Gustavo Lacerda

lglacerda@uepg.br

1 Food Science and Technology Graduate Program, State University of Ponta Grossa (UEPG), Av. Carlos Cavalcanti 4748 Uvaranas Campus, Ponta Grossa, PR CEP 84030-900, Brazil

2 Centre for Nuclear Energy in Agriculture, State University of São Paulo (USP), Av. Centenário, Luiz de Queiroz Campus, 303, Piracicaba 13900-470, Brazil based on black rice flours. Gamma radiation can be a useful tool to modify rice flours in order to suit various functionalities and to help meet the growing demands of the food industry.

Keywords Black rice - Irradiation · Thermal analysis · Gelatinisation · Morphology · Crystallinity

\section{Introduction}

Rice is one of the most widely consumed foods in the world, feeding almost one-third of the world's population [1]; it represents a major source of energy owing to its high concentration of starch and proteins, as well as containing minerals and B vitamins [2]. In recent years, pigmented rice varieties, such as black rice, have received increased attention from researchers and have become popular with consumers, due to their health-promoting properties [3].

Black rice contains high amounts of phenolic compounds, such as anthocyanins, which are associated with numerous health benefits due to their antioxidant activity; they also help to reduce the risk of developing chronic diseases such as cardiovascular disease, type II diabetes, obesity and cancer [4]. The natural colourants found in black rice, which can be used in the food industry as synthetic dye replacements, are dark purple anthocyanin pigments. Consequently, this pigmented rice can be used as a valuable ingredient for gluten-free cereal products with higher nutritional value, thereby providing extra health benefits to consumers.

Starch, which is the main carbohydrate present in rice, can be used to confer texture, structure and consistency to many food products. However, the uses of native starches are limited by their low solubility, high viscosity, thermal 
decomposition and high retrogradation tendency [5]. Thus, conventional sources of flours and starches (such as wheat, corn and rice) are modified to suit the specific needs of industries by adapting their physicochemical and functional properties, which are not available in their native form $[6,7]$. Chemical modification is commonly used but there is also a growing trend for the physical modification of starch [8].

Food irradiation represents an effective and environmentally friendly technology [9] that is aimed at improving food safety. In recent years, this technique has been widely researched. Its effects are known to preserve, reduce microbial load or sterilise, thereby increasing the shelf life of products and above all maintaining food quality. Its efficacy and safety are proven by official agencies including the Food and Agricultural Organisation (FAO), International Atomic Energy Agency (IAEA) and the World Health Organisation (WHO) [10].

Furthermore, irradiation has been used as a physical method to modify flours and starches in order to replace chemical or enzymatic modifications. According to Bhat and Karim [11], gamma radiation can alter the molecular structures, mainly of starch, causing its fragmentation by the penetration of ionising energy into the granules [12].

Starch plays an important role in the properties of rice and rice products. Gamma irradiation can provide different characteristics for rice flour, which need to be studied according to the final properties obtained. To date, there are few studies in the literature regarding the effect of irradiation on the degree of crystallinity, morphology, viscosity and thermal properties of pigmented rice varieties. Thus, the aim of this study was to understand the effects of gamma radiation on the thermoanalytical, structural and pasting properties of black rice flour.

\section{Experimental}

\section{Materials and sample preparation}

The black rice used in the experiments was purchased in the local supermarket in the city of Curitiba $\left(25^{\circ} 25^{\prime} 40^{\prime \prime}\right.$ S $\left.49^{\circ} 16^{\prime} 23^{\prime \prime} \mathrm{W}\right)$, Paraná, Brazil. The samples were ground and sieved through 60 mesh (particle size up to $250 \mu \mathrm{m}$ ) to obtain the black rice flour (BRF). This flour was separated and vacuum-packed in samples of about $200 \mathrm{~g}$ in small non-toxic metallic polyester bags with hermetic sealing and with light protection. The BRF had $10.64 \%$ moisture, $76.20 \%$ carbohydrate, $9.61 \%$ protein, $2.15 \%$ fat, $4.32 \%$ total dietary fibre and $1.41 \%$ ash, based on dry matter. All the samples were stored at $25^{\circ} \mathrm{C}$ for further analysis.

\section{Radiation of the BRF}

The black rice flour was subjected to gamma radiation at doses of $0,1,2$ and $3 \mathrm{kGy}$ at $0.221 \mathrm{kGy} \mathrm{h}^{-1}$ dose rate. The irradiation source was Cobalt 60 (Gammacell Excell 220 MDS Nordion), which was located in the Centre for Nuclear Energy in Agriculture at the University of São Paulo, Brazil (CENA/USP). Harwell Amber 3042 dosimeters were used to measure the radiation dose, and the uncertainty dose was less than $1 \%$ [13].

\section{Thermal analysis}

The thermogravimetric and derivative thermogravimetric curves (TG/DTG) were obtained as previously described [14] using a TGA-50 thermal analysis system (Shimadzu, Japan) under an oxidative atmosphere (synthetic air) flow of $150 \mathrm{~mL} \mathrm{~min}{ }^{-1}$ with a heating rate of $10{ }^{\circ} \mathrm{C} \mathrm{min}^{-1}$ from 30 to $600{ }^{\circ} \mathrm{C}$. The initial sample mass was about $6 \mathrm{mg}$, which was weighed in open alumina crucibles. All the mass loss percentages were determined using TA-60WS data analysis software.

The DSC curves were recorded according to Hornung et al. [15], using a DSC-Q200 model thermal analysis system (TA-Instruments) under airflow of $50 \mathrm{~mL} \mathrm{~min}^{-1}$ and at a heating rate of $10{ }^{\circ} \mathrm{C} \mathrm{min}{ }^{-1}$. Each sample (approximately $2.5 \mathrm{mg}$ ) was weighed directly in an aluminium crucible, and a volume of distilled water was added $(1: 4 \mathrm{w} / \mathrm{v})$ using a micropipette. The crucible was hermetically sealed and allowed to equilibrate for $60 \mathrm{~min}$ before testing. In order to obtain the DSC curves, the instrument was calibrated with $99.99 \%$ purity standard indium, m.p. $=156.6{ }^{\circ} \mathrm{C}, \Delta H=28.71 \mathrm{~J} \mathrm{~g}^{-1}$, and an empty aluminium crucible was used as reference. TA Universal Analysis 2000 software was used to analyse the main endotherm of the DSC curves for the initial $\left(T_{\mathrm{o}}\right)$, peak $\left(T_{\mathrm{p}}\right)$ and conclusion $\left(T_{\mathrm{c}}\right)$ temperatures, as well as the gelatinisation enthalpy $(\triangle H)$. The measurements were performed in triplicate.

\section{Morphological analysis}

The micro-images were obtained using a field emission gun-scanning electron microscope (FEG-SEM) (MIRA 3, Tescan, Czech Republic). The parameters were as follows: reading scale of 5 and $50 \mu \mathrm{m}$ with a tension of $15 \mathrm{kV}$ of field emission gun, which was generated by a lamp with a tungsten filament. The black rice flour samples were pulverised over a carbon tape. As flour is not conductive, it was necessary to metallise the samples with gold and palladium to promote the passage of electrons and to obtain the images using Image J software (Image J 1.47 to Windows $^{\mathrm{TM}}$ ) [16]. 


\section{X-ray diffractometry (XRD)}

The X-ray diffractograms (XRD) were obtained using an X-ray diffractometer (Ultima IV, Rigaku, Japan) with $\mathrm{CuK} \alpha$ radiation $(\lambda=1.5418 \AA$ ), a tension of $40 \mathrm{kV}$ and an electric current of $30 \mathrm{~mA}$. The analysis was performed at $20{ }^{\circ} \mathrm{C}$ in an angular range of $5-40^{\circ}(2 \theta)$, scanning speed of $2^{\circ} \min ^{-1}$ and a step of $0.02^{\circ}$. Equation (1) was used to calculate the relative crystallinity [7].

$X_{\mathrm{c}}=\frac{A_{\mathrm{p}}}{\left(A_{\mathrm{p}}+A_{\mathrm{b}}\right)} \times 100$

where $X_{\mathrm{c}}$ refers to the relative crystallinity; $A_{\mathrm{p}}$ refers to the crystallinity area of the X-ray diffractogram and $A_{\mathrm{b}}$ refers to the amorphous area of the diffractogram.

\section{Pasting properties}

Prior to determining the pasting properties of each sample, it was necessary to determine their moisture content in order to calculate the exact amount of dry matter to prepare a suspension with $8 \%$ of flour. An infrared moisture analyser (Sartorius AG, MA35 M, Germany) was used for the moisture determination. The pasting properties of the black rice flour samples were determined using a RVA-4 viscoamylograph (Newport Scientific Pvt. Ltd., Australia). A total mass of $28 \mathrm{~g}$ of the flour suspension was submitted to a controlled heating and cooling cycle under constant stirring, where it was held at $50{ }^{\circ} \mathrm{C}$ for $2 \mathrm{~min}$, heated from 50 to $95{ }^{\circ} \mathrm{C}$ at $6{ }^{\circ} \mathrm{C} / \mathrm{min}$ and held at $95{ }^{\circ} \mathrm{C}$ for $5 \mathrm{~min}$, cooled to 50 at $6{ }^{\circ} \mathrm{C} / \mathrm{min}$ and held at $50{ }^{\circ} \mathrm{C}$ for $2 \min [17]$.

\section{Statistical analysis}

The results are expressed as the mean \pm standard deviation and were analysed using STATISTICA 10 software (StatSoft Inc., Tulsa, OK, USA). One-way analysis of variance was used to study the effect of the gamma radiation on DSC, X-ray diffraction and pasting properties. Tukey's tests were conducted to determine differences between the means at 95\% confidence level $(p<0.05)$. Pearson's products $(r)$ were used to evaluate the strength of correlation between the response variables [10].

\section{Results and discussion}

\section{Thermogravimetry and derivative thermogravimetry (TG/DTG)}

Thermogravimetry is a thermoanalytical technique where the mass variation of a substance that is subjected to a controlled temperature variation is evaluated. The data that are obtained make it possible to study the decomposition of the matter and the periods of thermal stability [18]. The TG/DTG curves are presented in Fig. 1.

Flour is a complex mixture of different components, such as starch, non-starch polysaccharides, lipids, sugars, minerals and proteins, which influence its industrial use [19]. In addition, black rice flour contains a high content of fibres, minerals and phytochemicals, which are mainly flavonoids and anthocyanins [4]. These components present specific temperature ranges of thermal decomposition; thus, it is possible degradation occurs during different mass loss steps, which are detected by thermogravimetry.

Four mass losses were detected for the black rice flour samples, different from the characteristic behaviour of thermal decomposition of starches, which usually involves only three steps $[16,17]$. A slight displacement was observed for the second loss which occurred for the irradiated flours, compared to the control sample $(0 \mathrm{kGy})$. The values obtained from the TG/DTG curves are shown in Table 1.

The first loss occurred at similar temperatures for all the samples and corresponded to the loss of water and volatile compounds, as discussed by Bet et al. [16].

A slight increase in the thermal stability range was observed for the irradiated sample at a dose of $2 \mathrm{kGy}$ (until $189^{\circ} \mathrm{C}$ ). The second loss, with a mass loss between 4.01 and $4.56 \%$, started soon after the stability and was related to the thermal-oxidative decomposition, mainly of lipids [20]. The peak temperatures calculated by DTG were between 213 and $216{ }^{\circ} \mathrm{C}$, corresponding to the maximum rate of loss. Darfour et al. [21] reported that after the irradiation of cowpea meal at doses between 0.25 and $1.5 \mathrm{kGy}$, the flour had a greater capacity to absorb oil. In the present study, this may have been associated with the second loss, where there was an increase in the temperature range in which this event occurred in relation to the control sample.

The third and fourth losses referred to the decomposition and oxidation of organic matter, as reported by Lopes et al. [22], and occurred at similar temperatures for the control flour and the flours subjected to gamma irradiation. Corradini et al. [23] have suggested that the degradation of compounds such as fibres, proteins, cellulose $\left(310-360{ }^{\circ} \mathrm{C}\right)$ and hemicellulose $\left(240-310{ }^{\circ} \mathrm{C}\right)$ occurs during the third step. In addition, as pointed out by Beninca et al. [24], the depolymerisation of the starch chains that make up the flours occurs. The final residue contents after the thermal decomposition (ash) of the black rice flour were $1.41 \%$ for the control sample $(0 \mathrm{kGy})$ and $1.48,1.40$ and $1.68 \%$ for the samples submitted to gamma radiation at doses of 1,2 and $3 \mathrm{kGy}$, respectively. 

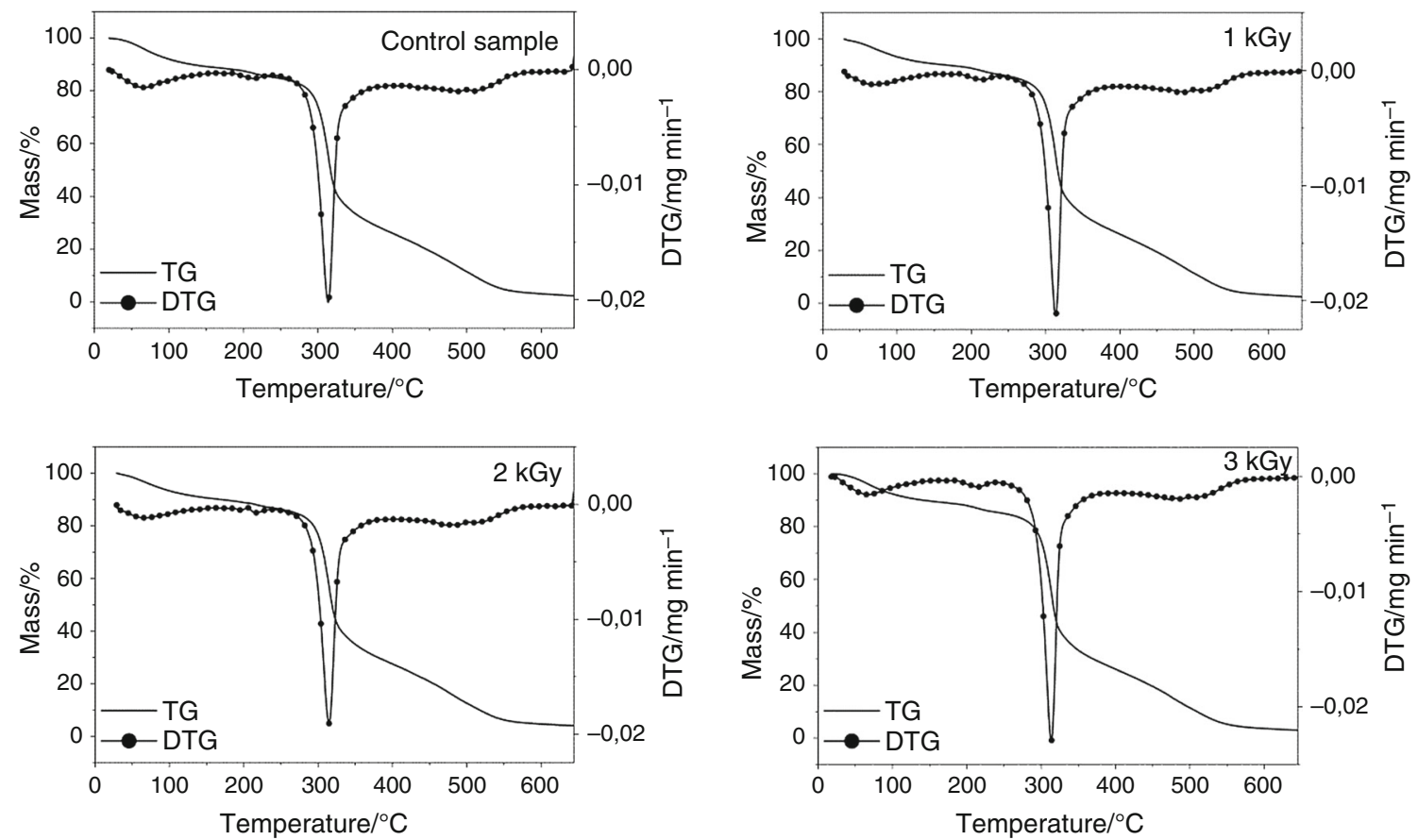

Fig. 1 TG/DTG curves of untreated and irradiated samples of black rice flour

Table 1 TG/DTG results of untreated and treated samples of black rice flour

\begin{tabular}{|c|c|c|c|c|}
\hline \multirow[t]{2}{*}{ Samples } & \multicolumn{2}{|c|}{ TG results } & \multicolumn{2}{|c|}{ DTG results } \\
\hline & Step & $\Delta m / \%$ & $\Delta T /{ }^{\circ} \mathrm{C}$ & $T \mathrm{p} /{ }^{\circ} \mathrm{C}$ \\
\hline \multirow[t]{5}{*}{ Control sample } & $1 \mathrm{st}$ & 10.64 & 30-148 & 67.13 \\
\hline & Stability & - & $148-186$ & - \\
\hline & 2nd & 4.01 & $186-238$ & 214.06 \\
\hline & $3 \mathrm{rd}$ & 61.79 & $238-406$ & 313.93 \\
\hline & 4th & 22.15 & $406-593$ & 488.06 \\
\hline \multirow[t]{5}{*}{1 kGy } & $1 \mathrm{st}$ & 9.08 & $30-144$ & 71.00 \\
\hline & Stability & - & $144-183$ & - \\
\hline & 2nd & 4.56 & $183-244$ & 213.56 \\
\hline & $3 \mathrm{rd}$ & 62.64 & $244-404$ & 313.51 \\
\hline & 4th & 22.24 & $404-592$ & 487.64 \\
\hline \multirow[t]{5}{*}{2 kGy } & $1 \mathrm{st}$ & 9.14 & $30-146$ & 67.35 \\
\hline & Stability & - & $146-189$ & - \\
\hline & 2nd & 4.32 & $189-247$ & 216.21 \\
\hline & 3 rd & 61.75 & $247-394$ & 314.60 \\
\hline & 4th & 23.39 & $394-593$ & 472.41 \\
\hline \multirow[t]{5}{*}{3 kGy } & $1 \mathrm{st}$ & 10.07 & 30-145 & 69.03 \\
\hline & Stability & - & $145-184$ & - \\
\hline & 2nd & 4.41 & $184-240$ & 215.38 \\
\hline & $3 \mathrm{rd}$ & 61.35 & $240-400$ & 313.54 \\
\hline & 4th & 22.49 & $400-597$ & 472.29 \\
\hline
\end{tabular}

$\Delta m$ mass loss $/ \%, \Delta T$ temperature range, $T_{\mathrm{p}}$ peak temperature

\section{Differential scanning calorimetry (DSC)}

Starch is an ingredient widely used in food systems to impart better texture, consistency and viscosity; it is the main component found in rice and confers important characteristics in the use of this cereal in a process known as gelatinisation [12]. This phenomenon can be studied using DSC to study the temperatures and the enthalpy involved in this endothermic event.

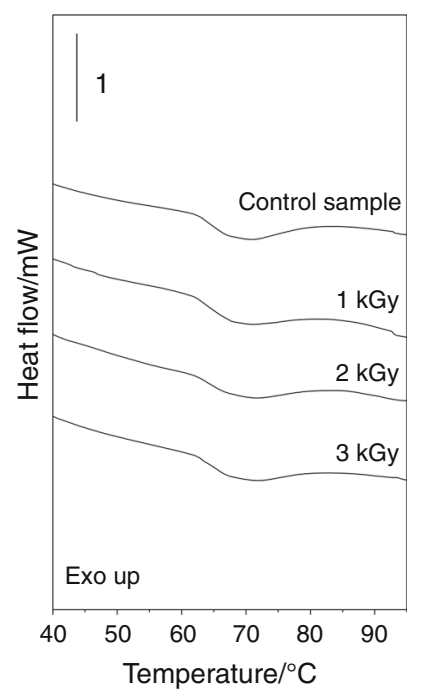

Fig. 2 DSC curves of untreated and irradiated samples of black rice flour 
The DSC curves of the black rice flour samples are presented in Fig. 2. All the samples showed slight changes in the thermal parameters $\left(T_{\mathrm{o}}, T_{\mathrm{c}}, T_{\mathrm{p}}\right.$, and $\left.\triangle H\right)$. For the irradiated samples (1, 2 and $3 \mathrm{kGy}), T_{\mathrm{c}}$ remained unchanged $(p>0.05)$, whereas $\mathrm{T}_{\mathrm{o}}, \mathrm{T}_{\mathrm{p}}$ and $\triangle H$ displayed a slight decrease when compared to the control sample (0 kGy) (Table 2).

The dose of $1 \mathrm{kGy}$ showed the lowest $T_{\mathrm{o}}\left(62.1^{\circ} \mathrm{C}\right)$ and $T_{\mathrm{p}}$ (68.4), whereas the control sample $(0 \mathrm{kGy})$ displayed the highest $T_{\mathrm{o}}\left(62.5^{\circ} \mathrm{C}\right)$ and $T_{\mathrm{p}}\left(69.7{ }^{\circ} \mathrm{C}\right)$. Regarding the behaviour of $\triangle H$, it decreased continuously with the increase in the irradiation dose $(p<0.05)$. Bao et al. [12] also concluded that the $\triangle H$ decreased in white rice flour after gamma irradiation. The enthalpy value was reported to decrease in wheat starches [25]. Rombo et al. [26] studied different flours and concluded that a decrease in required energy may have been due to the difference in starch granule sizes, or possibly to a difference in polymer chain lengths of the starch.

In the present study, the gamma irradiation caused a rupture in the black rice flour components, promoting a small variation in the gelatinisation temperature of the starch fraction. The samples submitted to 1 and $2 \mathrm{kGy}$ presented a slight decrease in the onset temperature $\left(T_{\mathrm{o}}\right)$. The reduction in the gelatinisation temperature is due to the cleavage of the amylopectin, which results in short chains and a reduction in the crystalline phase [27].

A slight decrease in the crystallinity, although without significant difference $(p>0.05)$ in relation to the nonirradiated flour shown by XRD (Table 2), may also have influenced the decrease in the gelatinisation enthalpy that was observed for the irradiated samples, which was due to the loss of the crystalline domain and double helices [6]. Furthermore, the $\triangle H$ and crystallinity parameters showed a positive correlation $(r=0.84)$, suggesting that $\triangle H$ was influenced by the crystallinity of the starch [28].

\section{X-Ray diffractograms (XRD)}

The X-ray diffractograms (Fig. 3) were used to verify the main peaks and to calculate the relative degree of crystallinity (\%) of each sample (Table 2). All the samples had clear A-type diffraction patterns with main reflections at $2 \theta \approx 15^{\circ}, 17^{\circ}, 18^{\circ}$ and $23^{\circ}$. Minor peak intensities were also observed at $2 \theta \approx 20^{\circ}$ and $27^{\circ}$. According to Ocloo et al. [29], this peak observed at $2 \theta \approx 20^{\circ}$ indicates the presence of some $\mathrm{V}$-type starch crystals in rice varieties.

In the present study, the gamma irradiation did not change the XRD patterns of the black rice flours, which was in agreement with other studies, such as [12] with white rice flour [29], with rice cultivars from Ghana [6], with rice starch and $[5,30]$ with cornstarch.

The non-irradiated flour showed a relative crystallinity higher than values reported for rice flour by Yu et al. [31]. Those authors reported that the differences found in the degree of relative crystallinity could have been associated with the presence of other components in the flour, such as proteins and lipids.

The relative crystallinity values obtained for the analysed samples ranged from 19.7 to $23.1 \%$ (Table 1). All the irradiated flour samples (1, 2 and $3 \mathrm{kGy})$ had decreased crystallinity compared with that of the non-irradiated flour sample (0 kGy). Chung and Liu [30] found lower crystallinity values with increasing doses of gamma radiation, and they attributed this fact to breaks in the crystalline regions inside the starch granules. However, the present study did not find significant $(p>0.05)$ effects of gamma irradiation on the relative crystallinity of the black rice flour samples.

According to Polesi et al. [6], many studies have found varying results for crystallinity. Irradiation degrades both the crystalline structure and the amorphous region of the starch granules, which leads to an increase or decrease in crystallinity depending on which region is most affected by

Table 2 DSC and relative crystallinity results of untreated and treated samples of black rice flour

\begin{tabular}{llllll}
\hline Sample & \multicolumn{2}{l}{ DSC gelatinisation } & & XRD \\
\cline { 2 - 5 } & $T_{\mathrm{o}} /{ }^{\circ} \mathrm{C}$ & $T_{\mathrm{p}} /{ }^{\circ} \mathrm{C}$ & $T_{\mathrm{c}}{ }^{\circ} \mathrm{C}$ & $\Delta H_{\text {gel }} / \mathrm{J} \mathrm{g}^{-1}$ & Degree of relative crystallinity/\% \\
\hline $0 \mathrm{kGy}$ & $62.5 \pm 0.04^{\mathrm{a}}$ & $69.7 \pm 0.23^{\mathrm{a}}$ & $77.8 \pm 0.30^{\mathrm{a}}$ & $4.4 \pm 0.12^{\mathrm{a}}$ & $23.1 \pm 0.05^{\mathrm{a}}$ \\
$1 \mathrm{kGy}$ & $62.1 \pm 0.03^{\mathrm{b}}$ & $68.4 \pm 0.47^{\mathrm{b}}$ & $77.3 \pm 0.82^{\mathrm{a}}$ & $3.7 \pm 0.37^{\mathrm{b}}$ & $22.5 \pm 3.41^{\mathrm{a}}$ \\
$2 \mathrm{kGy}$ & $62.2 \pm 0.05^{\mathrm{b}}$ & $69.7 \pm 0.09^{\mathrm{a}}$ & $77.6 \pm 0.15^{\mathrm{a}}$ & $3.3 \pm 0.07^{\mathrm{b}}$ & $21.2 \pm 0.60^{\mathrm{a}}$ \\
$3 \mathrm{kGy}$ & $62.5 \pm 0.06^{\mathrm{a}}$ & $68.6 \pm 0.17^{\mathrm{b}}$ & $77.1 \pm 0.10^{\mathrm{a}}$ & $3.3 \pm 0.05^{\mathrm{b}}$ & $19.7 \pm 2.08^{\mathrm{a}}$ \\
\hline
\end{tabular}

$T_{\mathrm{o}}$ "onset" initial temperature, $T_{\mathrm{p}}$ peak temperature, $T_{\mathrm{c}}$ "endset" conclusion temperature, $\Delta H_{\text {gel }}$ gelatinisation enthalpy, the degree of crystallinity was calculated as a percentage, and peaks are determined in $2 \theta$

Averages followed by the same letters in the same column do not differ statistically by Tukey's test $(p<0.05)$ 


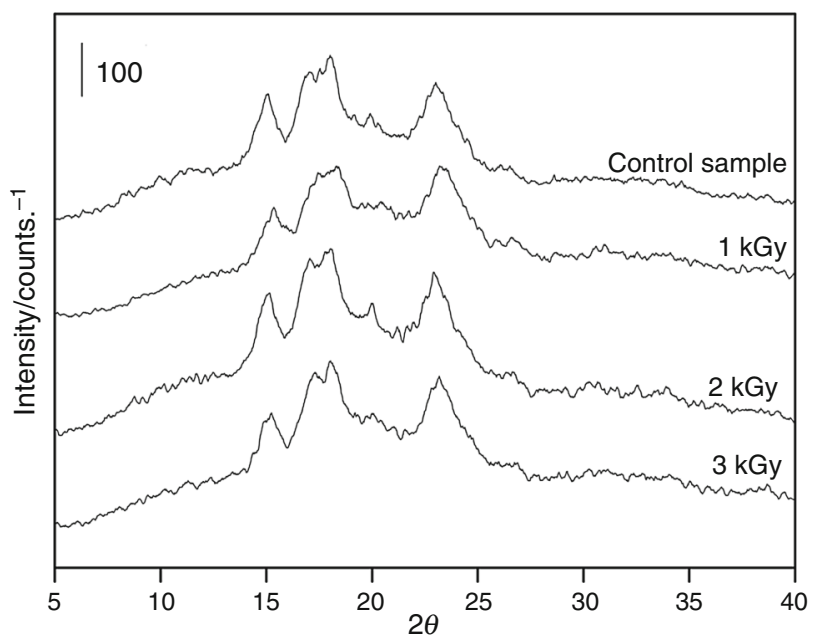

Fig. 3 X-ray diffraction patterns of untreated and irradiated samples of black rice flour

each dose. In addition to the botanical source, the dose rate plays an important role in crystallinity because greater recombination occurs among the starch molecules at low dosage rates [30].

\section{Field emission gun-scanning electron microscopy (FEG-SEM)}

The micro-images in Fig. 4 show an organic and heterogeneous composition, with particle agglomerates presenting irregular shapes and sizes that are characteristic of the samples of black rice flour. For the non-irradiated sample (0 kGy), the black rice flour was characterised by having a continuous structure with the starch granules surrounded by protein bodies and embedded in a cementing matrix [32]. Some changes occurred after gamma radiation such as cracks, pores and smaller fragments.

In the control sample $(0 \mathrm{kGy})$, the particles were larger, and surface cracking increased in line with increasing radiation doses; at the doses of 1,2 and $3 \mathrm{kGy}$, there was an accumulation of smaller fragments, which resulted from cracks, pores and irregularities on the surface.

Ashwar et al. [33] reported that cracks on the surface could be due to the effect of highly energetic and penetrating gamma radiation. These changes were associated with free radicals generated by gamma irradiation cleaving the glycosidic linkages of the large starch molecules, and some starch granules were fractured along the cleaved molecules, which may contribute to the formation of dextrin [34]. This kind of breakage resulted in increased numbers of small-sized particles in samples of the black rice flour.

\section{Pasting properties}

The pasting properties of the non-irradiated and irradiated black rice flour samples are presented in Fig. 5. Significant $(p<0.05)$ differences in the pasting properties were found in terms of temperature, peak viscosity, setback, breakdown and final viscosities in all the samples (Table 3). These results agreed with previous reports of the effects of irradiation on the pasting properties of flours made with rice cultivars [12, 29].

In the present study, the pasting properties decreased continuously with the increase in irradiation dose, except for the pasting temperature, which proportionally increased with the gamma radiation (Table 3). The pasting temperature was negatively correlated with peak, break, setback and final viscosity, which was in line with a previous study by Singh et al. [28]. Free radicals generated during the modification by irradiation of flour can promote the cleavage of the amylose and amylopectin glycosidic bonds, which are major components of starch, reducing its molecular mass and consequently decreasing the paste viscosity, thereby requiring higher temperatures for the formation of gel [6]. As found by Singh et al. [28], the pasting temperatures were higher than the $T_{o}$ obtained by DSC.

The decrease in these characteristic features (peak viscosity, setback, breakdown and final viscosities) of black rice flour samples after gamma irradiation can be associated with partial depolymerisation of the rice starch molecules due to chain ruptures [29]. This can be correlated with the results found by microscopy and X-ray powder diffraction analysis. According to Chung and Liu [30], a reduction in peak viscosity after irradiation might be due to the degradation of starch after irradiation, as well as the reduction in its swelling power.

Liu et al. [5] reported that the breakdown viscosity provides an indication of the stability of starch pastes and the tendency of starch granules to resist shear force during the heating process. However, the higher breakdown viscosity of the irradiated flour samples might indicate a disruption or weakening of the bonding forces (hydrogen bonds) in the starch granules [35].

According to Bhat et al. [35], the decrease in setback and final viscosities mainly occurs due to the reordering or polymerisation of leached amylose and amylopectin. This might decrease due to the degradation, as well as the shortening of the amylopectin branch chains. It is worth noting that setback and final viscosities are important parameters for the food industry. The lower viscosities of the studied samples suggest that irradiated black rice flours could be used in infant foods, for example. 

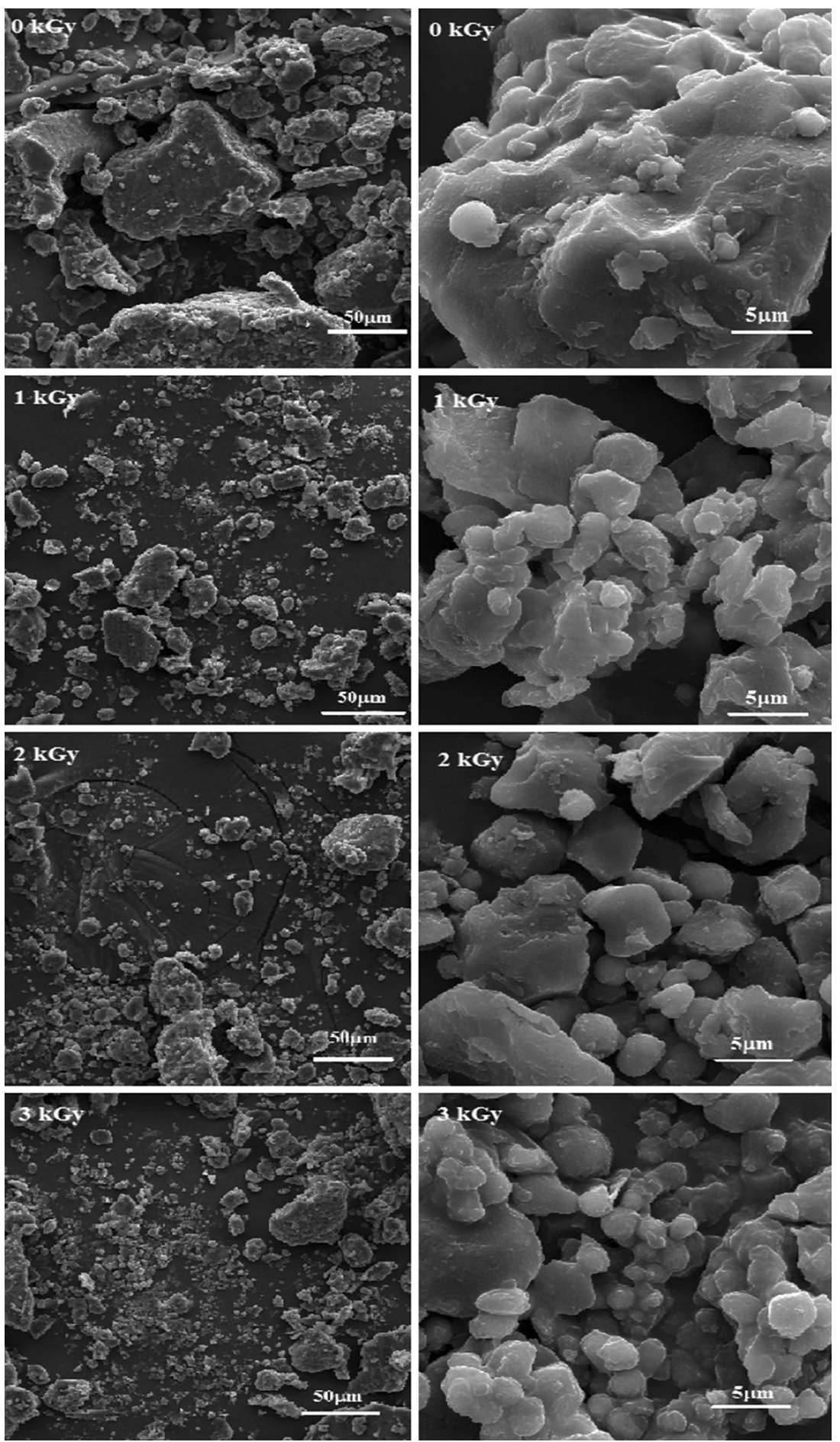

Fig. 4 FEG-SEM micro-images of untreated and irradiated samples of black rice flour

\section{Conclusion}

The effects of gamma radioisotope ${ }^{60} \mathrm{Co}$ on black rice flour were investigated considering thermoanalytical, structural and pasting properties. The thermogravimetric curves showed four mass losses. A small displacement was observed for the second loss, which occurred for the irradiated flours compared to the control sample. All the samples showed slight changes regarding thermal parameters $\left(T_{\mathrm{o}}, T_{\mathrm{c}}, T_{\mathrm{p}}\right.$ and $\left.\triangle H\right)$. For the irradiated samples, the $T_{\mathrm{o}}, T_{\mathrm{p}}$ and $\triangle H$ displayed a small decrease. 
Fig. 5 RVA pasting curves of untreated and irradiated samples of black rice flour

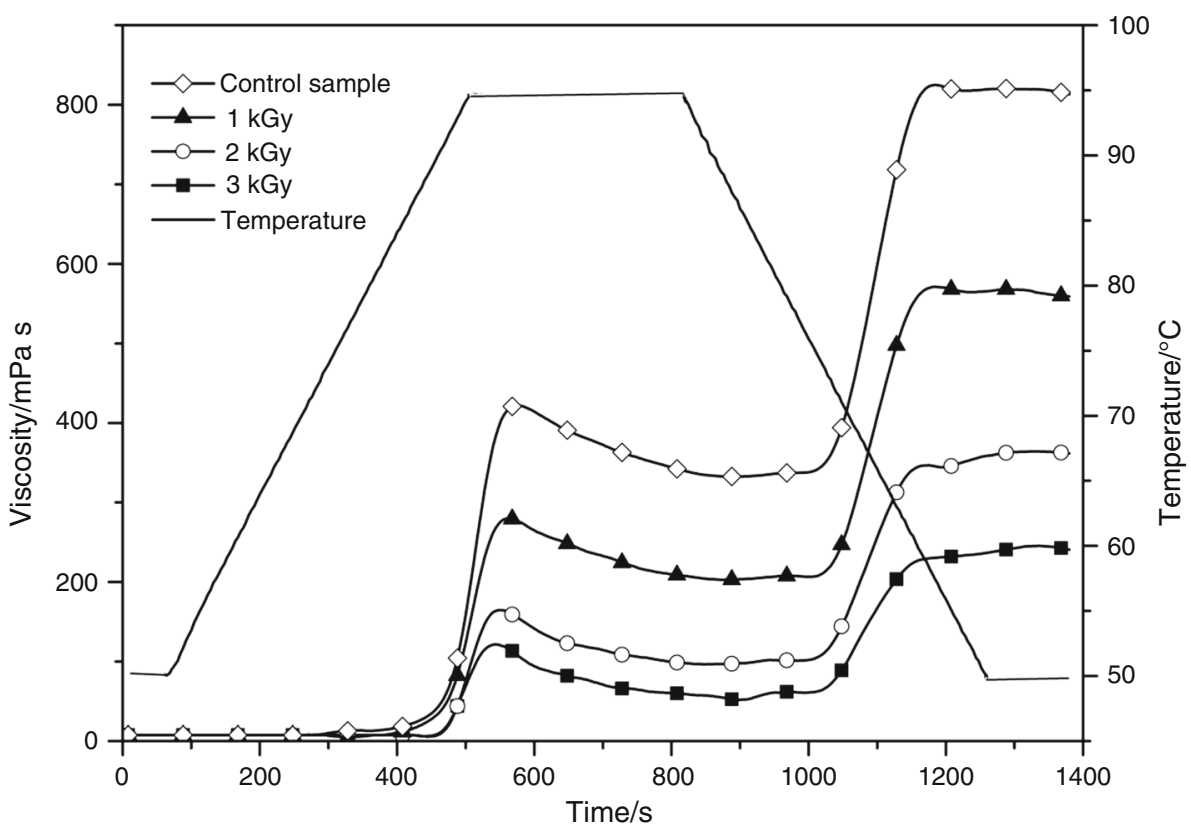

Table 3 RVA results of untreated and treated samples of black rice flour

\begin{tabular}{llllll}
\hline Sample & Pasting temperature $/{ }^{\circ} \mathrm{C}$ & Viscosity peak/mPa s & Setback/mPa s & Break/mPa s & Final viscosity/mPa s \\
\hline $0 \mathrm{kGy}$ & $92.9 \pm 0.21^{\mathrm{c}}$ & $422 \pm 2.82^{\mathrm{a}}$ & $481 \pm 0.41^{\mathrm{a}}$ & $90 \pm 1.20^{\mathrm{a}}$ & $813 \pm 0.21^{\mathrm{a}}$ \\
$1 \mathrm{kGy}$ & $93.7 \pm 0.28^{\mathrm{bc}}$ & $281 \pm 1.41^{\mathrm{b}}$ & $358 \pm 0.40^{\mathrm{b}}$ & $80 \pm 1.40^{\mathrm{b}}$ & $559 \pm 0.25^{\mathrm{b}}$ \\
$2 \mathrm{kGy}$ & $94.8 \pm 0.27^{\mathrm{ab}}$ & $166 \pm 2.83^{\mathrm{c}}$ & $267 \pm 0.28^{\mathrm{c}}$ & $71 \pm 1.21^{\mathrm{bc}}$ & $362 \pm 0.28^{\mathrm{c}}$ \\
$3 \mathrm{kGy}$ & $95.0 \pm 0.28^{\mathrm{a}}$ & $124 \pm 1.21^{\mathrm{d}}$ & $191 \pm 0.08^{\mathrm{d}}$ & $74 \pm 2.12^{\mathrm{c}}$ & $241 \pm 0.58^{\mathrm{d}}$ \\
\hline
\end{tabular}

mPa s "millipascal-second", s "second"

Averages followed by the same letters in the same column do not differ statistically by Tukey's test $(p<0.05)$

All the black rice flours exhibited A-type crystallinity pattern, and the gamma radiation did not change the XRD pattern or the degree of crystallinity. The micro-images obtained using FEG-SEM showed a composite of organic and heterogeneous material: after gamma radiation, some changes occurred such as cracks, pores and smaller fragments. The pasting properties (viscosity) decreased significantly with irradiation. The decrease in setback and breakdown viscosities after irradiation suggested the possibility of improving the quality of foods based on black rice flours.

Gamma radiation can be a useful tool to modify rice flours to suit various functionalities and to help to meet the growing demands of the food industry. Black rice is known as a potential source of anthocyanins, as well as being used as a natural colourant. This study showed that flours from gamma-irradiated black rice have the potential to be used in food formulations that require low viscosity such as porridges and infant foods. However, it also can be a valuable ingredient in gluten-free, cereal products with higher nutritional value, thereby providing extra health benefits to consumers.

Acknowledgements The authors are deeply grateful to the Coordination for the Improvement of Personnel in Higher Level (CAPES), Fundacão Araucária for funding and C-LABMU-UEPG for the infrastructure.

\section{References}

1. Hu Z, Tang X, Liu J, Zhu Z, Shao Y. Effect of parboiling on phytochemical content, antioxidant activity and physicochemical properties of germinated red rice. Food Chem. 2017;214:285-92.

2. Ziegler V, Ferreira CD, Goebel JTS, El Halal SLM, Santetti GS, Gutkoski LC, et al. Changes in properties of starch isolated from whole rice grains with brown, black, and red pericarp after storage at different temperatures. Food Chem. 2017;216:194-200.

3. Hao J, Zhu H, Zhang Z, Yang S, Li H. Identification of anthocyanins in black rice (Oryza sativa L.) by UPLC/Q-TOF-MS and their in vitro and in vivo antioxidant activities. J Cereal Sci. 2015;64:92-9. 
4. Zhang Y, Li P, Cheng L. Developmental changes of carbohydrates, organic acids, amino acids, and phenolic compounds in 'Honeycrisp' apple flesh. Food Chem. 2010;123(4):1013-8.

5. Liu T, Ma Y, Xue S, Shi J. Modifications of structure and physicochemical properties of maize starch by $\gamma$-irradiation treatments. LWT Food Sci Technol. 2012;46(1):156-63.

6. Polesi LF, Sarmento SBS, de Moraes J, Franco CML, CanniattiBrazaca SG. Physicochemical and structural characteristics of rice starch modified by irradiation. Food Chem. 2016;191:59-66.

7. Siqueira GLA, Hornung PS, Silveira AC, Lazzarotto SRS, Cordoba LP, Schnitzler E, Lazzarotto M. Impact of treatment with HCL/alcoholic in the modification of corn starch. J Therm Anal Calorim. 2017;129(3):1705-13.

8. Gul K, Singh AK, Sonkawade RG. Physicochemical, thermal and pasting characteristics of gamma irradiated rice starches. Int $\mathbf{J}$ Biol Macromol. 2016;85:460-6.

9. Pereira C, Calhelha RC, Antonio AL, Queiroz MJRP, Barros L, Ferreira ICFR. Effects of gamma radiation on chemical and antioxidant properties, anti-hepatocellular carcinoma activity and hepatotoxicity of borututu. Innov Food Sci Emerg Technol. 2014;26:271-7.

10. Ito VC, Alberti A, Avila S, Spoto M, Nogueira A, Wosiacki G. Effects of gamma radiation on the phenolic compounds and in vitro antioxidant activity of apple pomace flour during storage using multivariate statistical techniques. Innov Food Sci Emerg Technol. 2016;33:251-9.

11. Bhat R, Karim AA. Impact of radiation processing on starch. Compr Rev Food Sci Food Saf. 2009;8(2):44-58.

12. Bao J, Ao Z, J-1 Jane. Characterization of physical properties of flour and starch obtained from gamma-irradiated white rice. Starch-Stärke. 2005;57(10):480-7.

13. Ito VC, Ferreira Zielinski AA, Avila S, Spoto M, Nogueira A, Schnitzler E, Lacerda LG. Effects of gamma radiation on physicochemical, thermogravimetric, microstructural and microbiological properties during storage of apple pomace flour. LWT Food Sci Technol. 2017;78:105-13.

14. Hornung PS, Oliveira CS, Lazzarotto M, Lazzarotto SRS, Schnitzler E. Investigation of the photo-oxidation of cassava starch granules. J Therm Anal Calorim. 2016;123(3):2129-37.

15. Hornung PS, Cordoba LP, Lazzarotto SRS, Schnitzler E, Lazzarotto M, Ribani RH. Brazilian Dioscoreaceas starches. J Therm Anal Calorim. 2017;127(3):1869-77.

16. Bet CD, do Prado Cordoba L, Ribeiro LS, Schnitzler E. Common vetch (Vicia sativa) as a new starch source: its thermal, rheological and structural properties after acid hydrolysis. Food Biophys. 2016;11(3):275-82.

17. Kubiaki FT, Figueroa AM, Oliveira CS, Demiate IM, Schnitzler E, Lacerda LG. Effect of acid-alcoholic treatment on the thermal, structural and pasting characteristics of European chestnut (Castanea sativa, Mill) starch. J Therm Anal Calorim. 2016; doi:10.1007/s10973-016-5832-9.

18. Liu X, Wang Y, Yu L, Tong Z, Chen L, Liu H, Li X. Thermal degradation and stability of starch under different processing conditions. Starch-Stärke. 2013;65(1-2):48-60.

19. Puncha-arnon S, Uttapap D. Rice starch vs. rice flour: differences in their properties when modified by heat-moisture treatment. Carbohydr Polym. 2013;91(1):85-91.
20. Zhang Q, Saleh ASM, Chen J, Sun P, Shen Q. Monitoring of thermal behavior and decomposition products of soybean oil. J Therm Anal Calorim. 2014;115(1):19-29.

21. Darfour B, Wilson DD, Ofosu DO, Ocloo FCK. Physical, proximate, functional and pasting properties of flour produced from gamma irradiated cowpea (Vigna unguiculata, L. Walp). Radiat Phys Chem. 2012;81(4):450-7.

22. Lopes BDM, Demiate IM, Ito VC, de Oliveira CS, da Silva Carvalho Filho MA, Schnitzler E, Lacerda LG. Effects of partial in vitro digestion on properties of European chestnut (Castanea sativa Mill) flour. Thermochim Acta. 2016;640:36-41.

23. Corradini E, Imam SH, Agnelli JAM, Mattoso LHC. Effect of coconut, sisal and jute fibers on the properties of starch/gluten/ glycerol matrix. J Polym Environ. 2009;17(1):1-9.

24. Beninca C, Colman TAD, Lacerda LG, Filho MASC, Bannach G, Schnitzler E. The thermal, rheological and structural properties of cassava starch granules modified with hydrochloric acid at different temperatures. Thermochim Acta. 2013;552:65-9.

25. Cieśla K, Eliasson A-C. Influence of gamma radiation on potato starch gelatinization studied by differential scanning calorimetry. Radiat Phys Chem. 2002;64(2):137-48.

26. Rombo GO, Taylor JRN, Minnaar A. Irradiation of maize and bean flours: effects on starch physicochemical properties. J Sci Food Agric. 2004;84(4):350-6.

27. Kong X, Zhou X, Sui Z, Bao J. Effects of gamma irradiation on physicochemical properties of native and acetylated wheat starches. Int J Biol Macromol. 2016;91:1141-50.

28. Singh N, Kaur L, Sandhu KS, Kaur J, Nishinari K. Relationships between physicochemical, morphological, thermal, rheological properties of rice starches. Food Hydrocol. 2006;20(4):532-42.

29. Ocloo FCK, Owureku-Asare M, Agyei-Amponsah J, Agbemavor WSK, Egblewogbe MNYH, Apea-Bah FB, et al. Effect of gamma irradiation on physicochemical, functional and pasting properties of some locally-produced rice (Oryza spp) cultivars in Ghana. Radiat Phys Chem. 2017;130:196-201.

30. Chung HJ, Liu Q. Effect of gamma irradiation on molecular structure and physicochemical properties of corn starch. J Food Sci. 2009;74(5):C353-61.

31. Yu S, Ma Y, Menager L, Sun D-W. Physicochemical properties of starch and flour from different rice cultivars. Food Biotechnol. 2012;5(2):626-37.

32. Wu F, Chen H, Yang N, Wang J, Duan X, Jin Z, Xu X. Effect of germination time on physicochemical properties of brown rice flour and starch from different rice cultivars. J Cereal Sci. 2013;58(2):263-71.

33. Ashwar BA, Shah A, Gani A, Rather SA, Wani SM, Wani IA, Ahmed W, Masoodi FA, Gani A. Effect of gamma irradiation on the physicochemical properties of alkali-extracted rice starch. Radiat Phys Chem. 2014;99:37-44.

34. Kim H-Y, Park SS, Lim S-T. Preparation, characterization and utilization of starch nanoparticles. Colloids Surf B Biointerfaces. 2015;126:607-20.

35. Bhat NA, Wani IA, Hamdani AM, Gani A, Masoodi FA. Physicochemical properties of whole wheat flour as affected by gamma irradiation. LWT Food Sci Technol. 2016;71:175-83. 